\title{
Optimizing cycles of adsorption separation of gas mixtures
}

\author{
Akulinin E.I. \\ Technological Institute \\ Tambov State Technical University, TSTU \\ Tambov, Russia \\ akulinin-2006@yandex.ru \\ Dvoretsky D.S. \\ Technological Institute \\ Tambov State Technical University, TSTU \\ Tambov, Russia
}

\author{
Golubyatnikov O.O. \\ Technological Institute \\ Tambov State Technical University, TSTU \\ Tambov, Russia \\ Dvoretsky S.I. \\ Technological Institute \\ Tambov State Technical University, TSTU \\ Tambov, Russia
}

\author{
Skvortsov S.A. \\ Technological Institute \\ Tambov State Technical University, TSTU \\ Tambov, Russia
}

\begin{abstract}
Mathematical models of dynamics of pressure swing adsorption processes for the separation of synthesis gas (into hydrogen, carbon dioxide and carbon monoxide) and air (into oxygen, nitrogen and argon) have been developed. The models allow calculating the profiles of component concentrations and temperature of gas and solid phases, pressure and velocity of gas mixture along the height of adsorbent in relation to time. The models include the following equations: 1) processes of mass and heat transfer during the adsorption (desorption) of a sorptive $\left(\mathrm{H}_{2}, \mathrm{CO}_{2}, \mathrm{CO}\right.$ and $\left.\mathrm{O}_{2}, \mathrm{~N}_{2}, A r\right)$ by granulated zeolite adsorbents $5 A$ and $13 X$; 2) kinetics of compound diffusion transport of adsorbate and LangmuirFreundlich isotherm (for the synthesis gas separation), kinetics of external diffusion and Dubinin-Radushkevich isotherm (for the air separation); 3) the Ergun equation for the calculation of pressure and velocity of gas mixture in adsorbent. Using mathematical modeling the interrelation between the temperature, composition and pressure of the initial gas mixture and the purity, recovery ratio and temperature of the product gas (hydrogen and oxygen) has been established for a wide range of 'adsorption-desorption' cycle intervals and pressure during the adsorption stage. The dynamics of the adsorption of gas mixture components has been researched, as well as the nature of sorption and heat development over the height of adsorbent layer in the adsorber. The purity of the end product (hydrogen, oxygen) has been analyzed against the degree of productivity of a PSA unit. The paper presents formulations and solutions of optimisation problems for different regime variables (adsorption and desorption stage duration, pressure during adsorption and desorption stages, backflow coefficient) of the PSA unit with regard to the following criteria: 1) maximum purity (concentration) of the gas (hydrogen, oxygen) for a given productivity of the unit, 2) maximum productivity of the unit to meet the concentrated oxygen purity constraint.
\end{abstract}

Keywords- pressure swing adsorption; zeolite adsorbent; synthesis gas; air; dynamics modelling; optimisation

\section{INTRODUCTION}

In recent decades, cyclic adsorption processes and, in particular, pressure swing adsorption (PSA), as representing a special class of adsorption processes with cyclically varying pressure, have become the most common way of separating gas mixtures and concentrating the end products in them. As the name implies, PSA processes do not assume the presence of an external heat source, and the heat released at the adsorption stage is used for the desorption process of the adsorbate and, consequently, the regeneration of the adsorbent [1-3].

PSA-processes are widely used in the industry for the heatless separation of hydrocarbons, methane recovery, the concentration of hydrogen, oxygen, nitrogen, etc. in gas mixtures. One of the urgent problems in the field of adsorption separation is the production of hydrogen from hydrogencontaining process flows (gases of conversion and oxidation of hydrocarbons, refinery gases, synthesis gas, etc.) [2, 4] and air oxygenation in medical concentrators and onboard oxygen production units $[5,6]$. Typical substances that accompany hydrogen are nitrogen, carbon oxide and dioxide, methane; oxygen is usually accompanied by nitrogen and argon. The operation principle of a PSA unit is to cyclically alternate the selective processes of adsorption of components from the continuous flow of the gas mixture and desorption of these components from the adsorbent in parallel adsorbers. This creates a continuous flow enriched with one of the 
components (for example, hydrogen, oxygen, etc.) of the gas mixture at the outlet of the PSA unit.

The purpose of this work is the following: 1) the development of a mathematical model of the process of adsorption separation of a gas mixture with a cyclically variable pressure and the concentration of hydrogen or oxygen; 2) investigation of the effect of changes in the temperature, composition and pressure of the initial gas mixture on the purity, recovery and temperature of the product gas over a wide range of variation in the duration of the adsorption-desorption cycle and pressures in the adsorption and desorption stages; 3) study of the dynamics of the adsorption process of the gas mixture components and the nature of the movement of the sorption and thermal fronts along the height of the adsorbent bed in the adsorber, the connection between the productivity of the PSA unit and the purity of the product obtained (hydrogen, oxygen); 4) optimization of operating practices of PSA units for the separation of multicomponent gas mixtures and production of hydrogen (with a concentration of 99.99 vol.\%) and oxygen (with a concentration of $90 \ldots 95$ vol. $\%$ ) and degree of hydrogen concentration $\sim 65 \%$ and nitrogen extraction 99.9\%.

\section{NUMERICAL STUDY OF PRESSURE SWING ADSORPTION PROCESSES}

The process of hydrogen concentration by adsorption separation of gas mixture is carried out in a four-adsorber PSA unit with granulated synthetic zeolites $5 A$ and $13 X$ (Fig. 1) [4, $7,8]$. Air oxygenation is performed in a two-adsorber unit with granulated adsorbent $13 X[5,9]$.

The unit is designed to produce hydrogen with a concentration of up to $99.99 \%$ from a gas mixture containing hydrogen in an amount of $65 \pm 2$ vol.\%, carbon dioxide $\sim 34 \pm$ 2 vol.\% and carbon monoxide $\sim 1 \pm 2$ vol.\%. The initial gas mixture is fed to the unit after drying with an overpressure of $21 \times 10^{5} \mathrm{~Pa}$ and a temperature of $30{ }^{\circ} \mathrm{C}$. The pressure in the adsorbers $\mathrm{A}_{1} \mathrm{XA}_{4}$ is increased by opening the control valves $\left(v_{2}, v_{4}, v_{6}\right.$ and $\left.v_{8}\right)$, through which the gas is supplied to the adsorbent bed. The product hydrogen is withdrawn from the adsorbers via the controlled valves $\left(\mathrm{v}_{10}, \mathrm{v}_{12}, \mathrm{v}_{13}\right.$ and $\left.\mathrm{v}_{15}\right)$ and is sent to the consumer through the receiver $R$. Counterflow regeneration of the adsorbent in the adsorbers is performed by opening the valves $\left(\mathrm{v}_{11}, \mathrm{v}_{14}, \mathrm{v}_{16}\right.$ and $\left.\mathrm{v}_{18}\right)$ through which the hydrogen-enriched gas mixture is fed to adsorbent layer for desorption of a sorptive, and the purge gas is released from the desorption stage through the valves $\mathrm{v}_{3}, \mathrm{v}_{5}, \mathrm{v}_{7}$ and $\mathrm{v}_{9}$, for subsequent use. The coordinated operation of the valve system ensures that each adsorber of the unit sequentially runs each PSA cycle: raising the pressure in the adsorber to the nominal (operating) value (at the adsorption stage) and carrying out the adsorption stage, releasing the gas, reducing the pressure to the nominal value (at the desorption stage), and the desorption stage (regeneration of the adsorbent).

The two-adsorber PSA unit for the separation of atmospheric air and oxygen concentration operates on a similar principle.

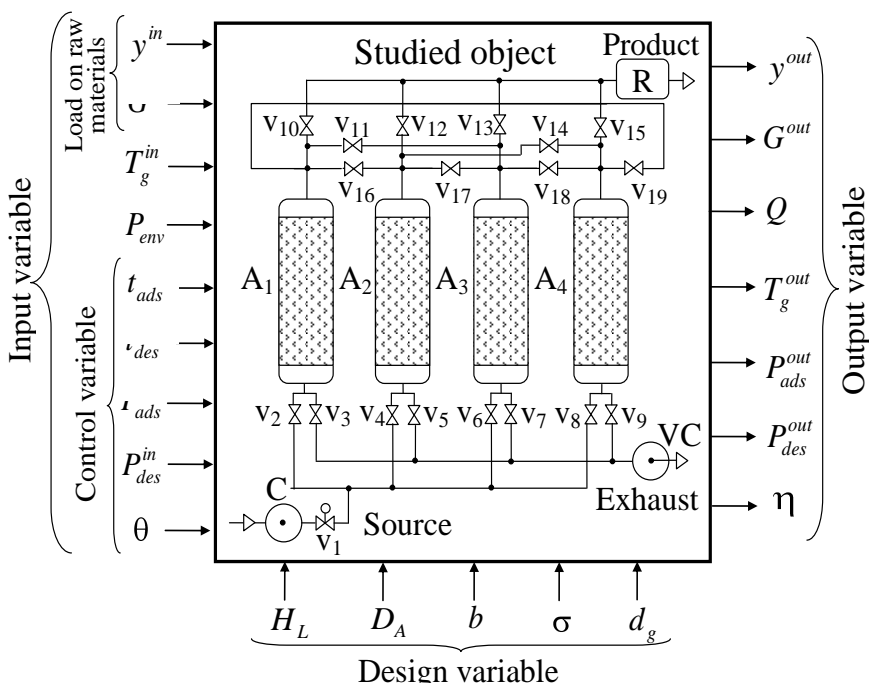

Fig. 1. A four-adsorber PSA unit for hydrogen concentration: $A_{1}-A_{4}-$ adsorbers, $\mathrm{v}$ - control valves, $R$ - receiver

The input variables in these units are the following: a raw material load $x_{L}=\left\{y^{i n}, G^{i n}\right\}, y^{i n}, G^{i n}-$ composition and consumption rate of the initial gas mixture (or air); vector of controls $u=\left\{t_{a d s}, t_{d e s}, P_{a d s}^{i n}, P_{d e s}^{i n}, \theta\right\}, t_{a d s}, t_{d e s}$ - duration of adsorption and desorption stages; $P_{a d s}^{i n}, P_{d e s}^{i n}$ - pressure at adsorption and desorption stages, $P_{e n v}$ - ambient pressure and $T_{g}^{i n}$ - temperature of the initial gas mixture at the inlet into adsorbers. The output variables include $y_{1}^{\text {out }}$ concentrations of product gases (hydrogen, oxygen) and accessory agents; the extraction rate $\eta$ of a sorptive (carbon dioxide, carbon monoxide, nitrogen), productivity $Q$ of a PSA unit; $T_{g}^{\text {out }}$ temperature, $P_{\text {ads }}^{\text {out }}, P_{\text {des }}^{\text {out }}$ - pressures and $G^{\text {out }}$ - consumption rate of a product gas (hydrogen, oxygen).

The following mass and heat exchange processes occur during the adsorption of predominantly $\mathrm{CO}_{2}, \mathrm{CO}$, and $\mathrm{N}_{2}$ with zeolite adsorbents in PSA adsorbers: a) diffusion of $\mathrm{H}_{2}, \mathrm{CO}_{2}$, $\mathrm{CO}$ and $\mathrm{O}_{2}, \mathrm{~N}_{2}$ in the gas mixture flow; 2) mass exchange and heat exchange between the gas phase $\left(\mathrm{H}_{2}, \mathrm{CO}_{2}, \mathrm{CO}\right.$ and $\mathrm{O}_{2}$, $\mathrm{N}_{2}$ ) and adsorbent; 3) adsorption of $\mathrm{CO}_{2}, \mathrm{CO}$ and $\mathrm{N}_{2}$ on the surface and in micropores of zeolite adsorbent granules with release of heat, and desorption of $\mathrm{CO}_{2}, \mathrm{CO}$ and $\mathrm{N}_{2}$ from micropores and from the surface of granules with heat absorption. Analysis of the results of the physical modeling of these processes showed that the diffusion of $\mathrm{H}_{2}, \mathrm{CO}_{2}, \mathrm{CO}, \mathrm{O}_{2}$, $\mathrm{N}_{2}$ and the propagation of heat in the gas and solid phases are carried out mainly in the axial direction relative to the flow of the gas mixture in the adsorber (i.e., the height of the adsorbent). The process of gas mixture enrichment with hydrogen during adsorption of $\mathrm{CO}_{2}$ and $\mathrm{CO}$ by granulated zeolite adsorbent is carried out in the mixed-diffusion region (determined by the total mass transfer coefficient), and air oxygenation during adsorption of $N_{2}$ - in the external diffusion region (determined by the coefficient of external mass 
transfer). Both processes are determined by equilibrium ratios of the concentrations of $\mathrm{H}_{2}, \mathrm{CO}_{2}, \mathrm{CO}$ and $\mathrm{O}_{2}, \mathrm{~N}_{2}$ in phases.

In the mathematical description of the processes of enrichment of synthesis gas with hydrogen and atmospheric air with oxygen, the following assumptions were made: 1) synthesis gas (contains 1 - hydrogen $\mathrm{H}_{2}$ with a concentration of $65 \pm 2$ vol.\%, 2 - carbon dioxide $\mathrm{CO}_{2}$ at a concentration of $34 \pm 2$ vol.\%, 3 - carbon monoxide $C O$ with a concentration of $1 \pm 0.5$ vol.\%) and atmospheric air (contains 1 - oxygen $\mathrm{O}_{2}$ at a concentration of $20.8 \pm 2$ vol.\%, 2 - nitrogen $N_{2}$ with a concentration of $78.2 \pm 2$ vol.\%, 3 - argon $A r$ with a concentration of $1 \pm 0.5$ vol. $\%$ are three-component (the concentration of other substances (impurities) does not exceed $0.001 \%$ ) and are considered to be ideal gases, which is acceptable at a pressure of up to $200 \times 10^{5} \mathrm{~Pa}$ in the adsorber [10]; 2) the diffusion of $\mathrm{H}_{2}, \mathrm{CO}_{2}, \mathrm{CO}, \mathrm{O}_{2}, \mathrm{~N}_{2}$ and the propagation of heat in the gas and solid phases occur only in the axial direction of the gas mixture flow in the adsorber (along the height of the adsorbent); 3) granulated zeolites $5 \mathrm{~A}$ (for separation of synthesis gas) and $13 X$ (for separation of atmospheric air) with the diameter of granules of 2 and $1 \mathrm{~mm}$, porosity coefficient $\sim 0.375$ and $\sim 0.394$, respectively, are used as adsorbents $[1-3,11]$; 4) the adsorption equilibrium (isotherms of adsorption) is described by the LangmuirFreundlich equation (for the separation of synthesis gas and hydrogen concentration) and Dubinin-Radushkevich equation (for air separation and oxygen concentration); 5) desorption branches of isotherms for the $\mathrm{H}_{2}, \mathrm{CO}_{2}, \mathrm{CO}$ adsorption by zeolite $5 \mathrm{~A}$ and and for $\mathrm{O}_{2}, \mathrm{~N}_{2}, \mathrm{Ar}$ adsorption by zeolite $13 \mathrm{X}$ coincide with adsorption branches [3]; 6) the gas temperature in the receiver is equal to the temperature of the gas at the outlet from the adsorber, the thermal losses to the environment are negligible.

In accordance with the assumptions, the mathematical description of the process of separation of a three-component gas mixture and the concentration of hydrogen (oxygen) includes the following equations [4]: 1) a nonlinear partial differential equation of parabolic type, describing the component material balance (1 - hydrogen $\mathrm{H}_{2}, 2$ - carbon dioxide $\mathrm{CO}_{2}, 3$ - carbon monoxide $\mathrm{CO}$ ) in the gas phase flow and in the gas-air flow ( 1 - oxygen $\mathrm{O}_{2}, 2$ - nitrogen $N_{2}, 3$ argon $A r$ ), taking into account axial mixing of the $k$-th component of the gas mixture in the adsorbent layer, and 2) a nonlinear differential equation in ordinary derivatives, describing the adsorption-desorption kinetics; 3) nonlinear partial differential equations of parabolic type, describing the propagation of heat in the gas and solid phases, taking into account the convective component and thermal conductivity; 4) a nonlinear partial differential equation describing the change in the flow velocity along the height of the adsorbent; 5) the Ergun differential equation in ordinary derivatives, which describes the change in the pressure of the gas mixture along the height of the adsorbent.

To solve the system of partial differential equations with the corresponding initial and boundary conditions [4], various methods were used: the finite element method in the Matlab software and the method of lines. According to the method of lines, the derivatives with respect to the spatial coordinate were replaced by finite-difference formulas and the solution of the boundary-value problem (the system of differential equations in ordinary derivatives) was searched by the fourthorder Runge-Kutta method with automatic step selection along a certain family of lines.

To analyze the accuracy of mathematical models of the adsorption separation of gas mixtures and air, the relative error of the mismatch between the calculated values for the model and the experimental values of the concentration of the product (hydrogen, oxygen) in the 'steady state' (after 15-30 operating cycles of the PSA) was calculated. The maximum error in the mismatch of the experimental and the calculated data was used, i.e.

$$
\delta_{\max }=\max _{t}\left(y_{1}^{\text {out }}(t)-y_{1}^{\text {out }, e}(t) \mid / y_{1}^{\text {out }, e}(t)\right] 100 \% .
$$

The value $\delta_{\max }$ (with regard to hydrogen and oxygen) did not exceed $11.5 \%$ (Fig. 2 and 3), which allows using a mathematical model for technological calculation, optimization of cycles and designing PSA installations for separation of multicomponent gas mixtures and concentration of product gases (hydrogen and oxygen).

Computational experiments were carried out to numerically study the effect of disturbance and regime variables on the output coordinates of the adsorption separation of the gas mixture in a four-adsorber PSA unit for hydrogen concentration from synthesis gas and a two-adsorber PSA unit for oxygen concentration from atmospheric air.

Fig. 4 and 5 show the concentrations $y_{1}^{\text {out }}$ and the rate of concentration of hydrogen $\eta$ as a function of the duration $t_{a d s}$ of the adsorption stage (Fig. 4) and the consumption of product hydrogen $G^{\text {out }}$ at the outlet of the PSA unit (Fig. 5) at a ratio of $t_{d e s} / t_{a d s}=0.5$, the temperature of the initial mixture of $T_{g}^{i n}=30^{\circ} \mathrm{C}$ and the $C \mathrm{O}_{2}$ concentration in the initial mixture $y_{2}^{\text {in }}=25,34$ and 45 vol. $\%$.

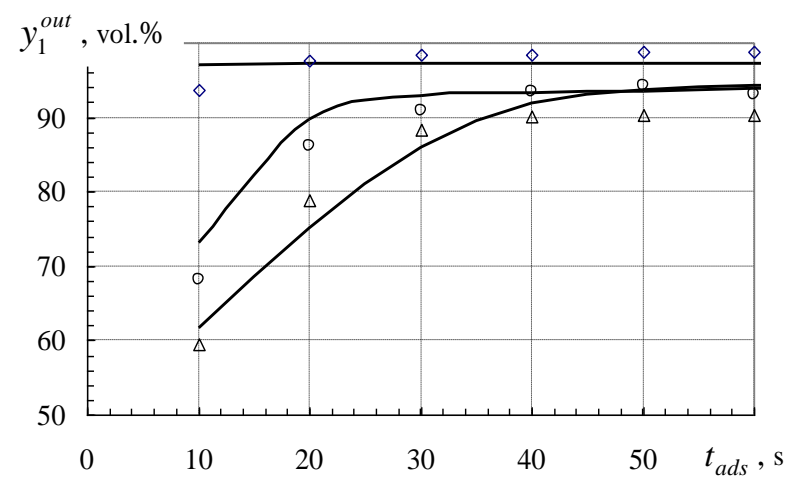

Fig. 2. Dynamics of hydrogen concentration change at the outlet of the fouradsorber PSA unit at $\mathrm{CO}_{2}$ concentration in the initial mixture:

1 - 10 vol. $\% ; 2$ - 40 vol. $\% ; 3$ - 50 vol. $\%$

$(\diamond, \circ, \Delta$ - experiment, solid line - calculation by model) 


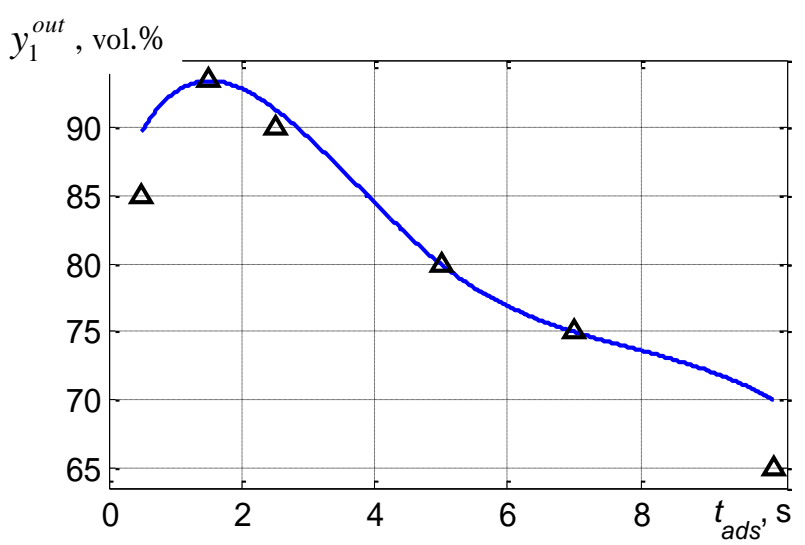

Fig. 3. The dynamics of the change in the oxygen concentration $y_{1}^{\text {out }}$ at the outlet of the two-adsorber PSA unit in relation to the duration

of the adsorption-desorption stage $t_{a d s}$

( $\Delta$-experiment, solid line-calculation by model)

The analysis of the dependences in Fig. 4 proves that for each value of the concentration of $\mathrm{CO}_{2}$ in the initial gas mixture, there is a range of values $\left[t_{\text {ads }} ; \overline{t_{a d s}}\right]$ of the duration of the adsorption stage, at which the maximum concentration $y_{1}^{\text {out }}$ and the rate of concentration $\eta$ of product hydrogen is reached (for example, for $y_{2}^{i n}=34$ vol. $\%$ ) in the interval from 38 to 46 seconds (Fig. 4a, curve 2). At a shorter duration of the adsorption stage, sufficient regeneration of the adsorbent is not ensured (for example, for $y_{2}^{i n}=34$ vol. $\%$ in the interval from 25 to $37 \mathrm{~s}$ (Fig. 4a, curve 2), and for longer duration $t>\overline{t_{\text {ads }}}$ the concentration of hydrogen at the unit outlet decreases as a result of exhaustion of adsorption capacity of the adsorbent (for example, for $y_{2}^{i n}=34$ vol. $\%$ in the interval from 47 to $200 \mathrm{~s}$ (Fig. 4a, curve 2)), which leads to a decrease in the efficiency of the PSA unit. It should be noted that an increase in the concentration of $\mathbf{C O}_{2}$ in the initial gas mixture by $\sim 1.8$ times (from 25 to 45 vol.\%) shifts the range $\left[t_{\text {ads }} ; \overline{t_{\text {ads }}}\right]$, at which the maximum value of the concentration $y_{1}^{\text {out }}$ is reached, in the direction of increasing the duration of the adsorption stage $t_{a d s}$ and reducing it by four times (Fig. 4a, for curve 1 , the range is $16 \mathrm{~s}$ - an interval from 35 to $50 \mathrm{~s}$, for curve 3 - the range is $4 \mathrm{~s}$ from 72 to $75 \mathrm{~s}$ ). It also shifts the range $\left[t_{a d s} ; \overline{t_{a d s}}\right]$, at which the maximum rate of concentration of hydrogen $\eta$ is reached, in the direction of decreasing the duration of the adsorption stage $t_{\text {ads }}$ (Fig. 4b , for curve 1 - an interval from 100 to $112 \mathrm{~s}$, for curve 3 - an interval from 89 to $101 \mathrm{~s})$.

As follows from the analysis of the graphs in Fig. 5, the purity of the product decreases with the increase of product hydrogen consumption by the PSA unit the faster, the higher is the $\mathrm{CO}_{2}$ concentration in the initial gas mixture. This is explained by the faster exhaustion of the adsorption capacity of the adsorbent. Dependences are almost linear, with the greatest sensitivity to a change in flow observed at the least favorable concentration of $\mathrm{CO}_{2}$ (45 vol.\%) in the initial gas mixture, and its decrease to 25 vol.\% allows to significantly increase the productivity of the unit with a slight loss of product purity (due to the fact that deeper desorption of carbon oxides by the hydrogenenriched gas mixture is ensured).

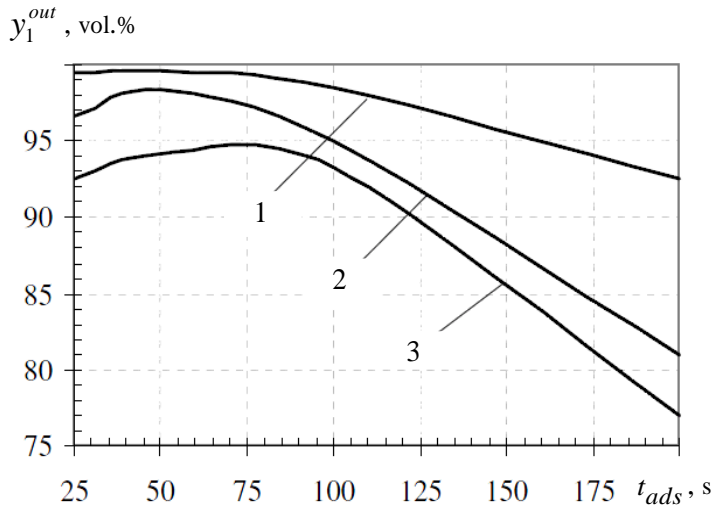

a)

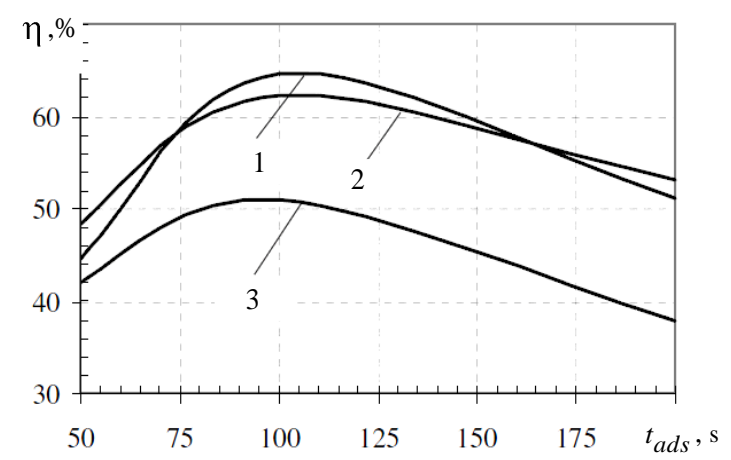

b)

Fig. 4. Dependence of the concentration $y_{1}^{\text {out }}$ (a) and the rate of concentration (b) of hydrogen on the duration $t_{a d s}$ of the adsorption stage at the concentration of $\mathrm{CO}_{2}$ in the initial mixture:

$1-y_{2}^{i n}=25$ vol. $\% ; 2-y_{2}^{i n}=34$ vol. $\% ; 3-y_{2}^{i n}=45$ vol. $\%$

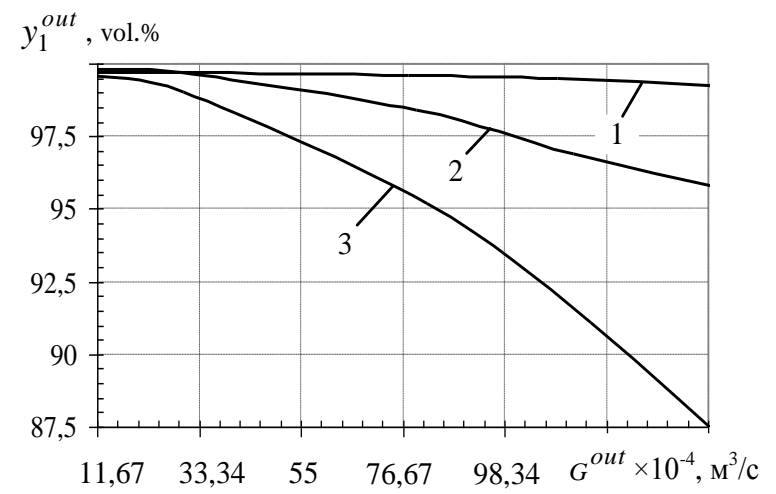

Fig. 5. Dependence of concentration $y_{1}^{\text {out }}$ on the consumption of product hydrogen at the outlet of the PSA unit at the concentration of $\mathrm{CO}_{2}$ in the initial mixture: $1-y_{2}^{\text {in }}=25$ vol. $\% ; 2-y_{2}^{i n}=34$ vol. $\% ; 3-y_{2}^{\text {in }}=45$ vol. $\%$ 
Fig. 6 and 7 show the dependence of the oxygen concentration $y_{1}^{\text {out }}$ and the degree of nitrogen recovery $\eta$ on the duration of the adsorption stage $t_{a d s}$ (Fig. 6) and the dynamics of oxygen concentration $y_{1}^{\text {out }}$ on the operating time $t$ of the PSA unit at a ratio of $t_{d e s} / t_{a d s}=2$, pressures at adsorption and desorption stages of $P_{a d s}^{i n}=3 \times 10^{5} \mathrm{~Pa}$, $P_{d e s}^{i n}=1 \times 10^{5} \mathrm{~Pa}$, temperature the initial mixture is $T_{g}^{i n}=20^{\circ} \mathrm{C}$, the load $G^{i n}=17 \times 10^{-5} \mathrm{~m}^{3} / \mathrm{s}$ and the concentration of nitrogen $N_{2}$ in the initial mixture $y_{2}^{i n}=68.2 ; 73.2 ; 78.2 ; 83.2 \%$ and 88.2 vol. $\%$.

Analysis of the dependencies in Fig. 3 shows that for each value of nitrogen concentration $N_{2}$ in the initial gas-air mixture, there is also a range of values $\left[t_{a d s} ; \overline{t_{a d s}}\right]$ of the duration of the adsorption stage, at which the maximum value of the product oxygen concentration $y_{1}^{\text {out }}$ is reached (for example, for $y_{2}^{\text {in }}=88.2$ vol.\% in the interval from 1 to $19 \mathrm{~s}$ (Fig. 6a, curve 3)) and the rate of nitrogen recovery $\eta$ (for example, for $y_{2}^{i n}=88.2$ vol.\% in the interval from 1 to $25 \mathrm{~s}$ (Fig. 6b, curve 3)). With a longer duration of the adsorption stage $t>\overline{t_{a d s}}$, the oxygen concentration at the unit outlet decreases as a result of depletion of the adsorption capacity of the adsorbent (for example, for $y_{2}^{i n}=88.2$ vol. $\%$ in the interval from 19 to $85 \mathrm{~s}$ (Fig. 3a, curve 3)) and reaches the initial value (for example, for $y_{2}^{i n}=88.2$ vol. $\%$ in the range from 85 to $100 \mathrm{~s}$ (Fig. 6a, curve 3)). It should be noted that an increase in the nitrogen concentration $N_{2}$ in the initial gas-air mixture $~ 1.3$ times (from 68.2 to $88.2 \%$ (vol.)) leads to an increase in the range of values of the duration of the adsorption stage $t_{a d s}$, at which the maximum concentration of product oxygen $y_{1}^{\text {out }}$ is reached $(\sim 2.7$ times, from 7 to 19 seconds, Figure $6 \mathrm{a}$, curves 1 and 3 ) and the rate of nitrogen recovery $\eta$ is also maximal ( $\sim 3.1$ times, from 8 to $25 \mathrm{~s}$ in Fig. 6b, curves 1 and 3).

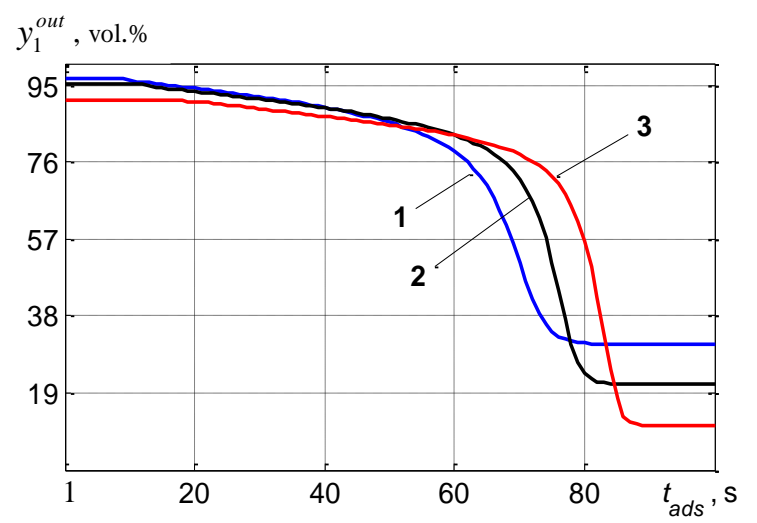

a)

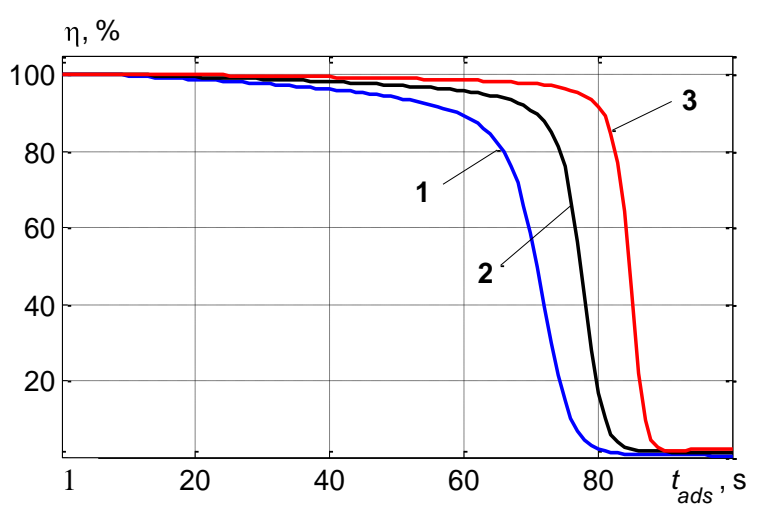

b)

Fig. 6. Dependence of the concentration $y_{1}^{\text {out }}$ (a) and the rate of nitrogen recovery (b) on the duration of the adsorption stage $t_{a d s}$ in the 'steady-state regime' of the unit at a concentration of $N_{2}$ in the initial mixture: $1-y_{2}^{i n}=$ 68.2 vol. $\% ; 2-y_{2}^{i n}=78.2$ vol. $\% ; 3-y_{2}^{i n}=88.2$ vol. $\%$

From the analysis of the dynamics of oxygen changes (Fig. 7) it follows that a decrease in the concentration of product oxygen $y_{1}^{\text {out }}$ is proportional to an increase in the nitrogen concentration in the initial gas-air mixture. With a decrease in the inlet nitrogen concentration by 10 vol. $\%$, the oxygen concentration $y_{1}^{\text {out }}$ increases by $\approx 3$ vol. $\%$.

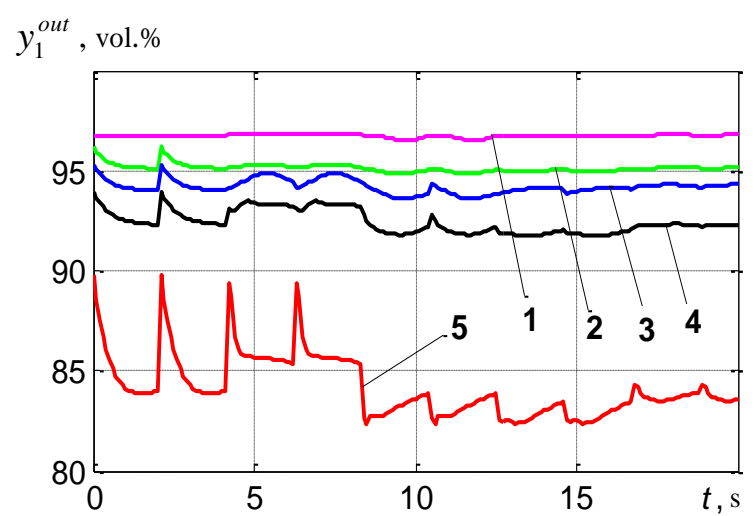

Fig. 7. Dynamics of the oxygen concentration at the outlet from the unit at the inlet concentration of $N_{2}$ in the gas mixture: $1-y_{2}^{i n}=68.2$ vol. $\%$;

$2-y_{2}^{i n}=73.2$ vol. $\% ; 3-y_{2}^{i n}=78.2$ vol. $\% ; 4-y_{2}^{i n}=83.2$ vol. $\%$; $5-y_{2}^{i n}=88.2$ vol. $\%$

Numerical studies have made it possible to determine the most significant disturbances $x_{L}=\left\{y^{\text {in }}, G^{\text {in }}\right\}$ and regime parameters $u=\left\{t_{a d s}, t_{d e s}, P_{a d s}^{i n}, P_{d e s}^{i n}, \theta\right\}$, as well as the range of admissible regime parameters necessary for solving the problems of optimizing PSA unit's cycles. 


\section{OPTIMISATION OF CYCLES OF THE PRESSURE SWING ADSORPTION UNIT}

Let us consider some problems of optimization of cycles of PSA units for the separation of gas mixtures and atmospheric air.

First, we formulate the problem of determining the regime parameters $u$ of the PSA unit - pressure $P_{a d s}^{i n *}$ at the adsorption stage and the duration of the adsorption stage $t_{a d s}^{*}$ such that the average value of the product hydrogen concentration $y_{1}^{\text {out }}$ at the time interval $\left[0, t_{s t}\right]$ corresponding to the 'steady-state' operation of the PSA unit reaches its maximum value, i.e.

$$
I\left(u^{*}\right)=\frac{1}{t_{s t}} \int_{0}^{t_{s t}} y_{1}^{\text {out }}\left(u^{*}\right) d t=\max _{u=\left\{P_{a d s}^{i n}, t_{a d s}\right\}}\left(\frac{1}{t_{s t}} \int_{0}^{t_{s t}} y_{1}^{\text {out }}(u) d t\right) .
$$

These are linked by the equations of a mathematical model of dynamics of a process of adsorption separation of a gas mixture and concentration of hydrogen [4], and imply constraints on the concentration of product hydrogen and unit's productivity. The formulated optimization problem belongs to the class of non-linear programming problems, for which the method of penalty functions (interior point method) and sequential quadratic programming was used [12]. As the nominal (working) mode of operation of the PSA unit, when the gas mixture was separated and hydrogen concentrated, the following process parameters were taken: $y_{2}^{i n}=34$ vol. $\%$, $G^{i n}=20.4 \times 10^{-3} \mathrm{~m}^{3} / \mathrm{s}, T_{g}^{i n}=30^{\circ} \mathrm{C}, t_{a d s}=42.5 \mathrm{~s}, P_{a d s}^{i n}=15.8 \mathrm{X}$ $10^{5} \mathrm{~Pa}, t_{d e s} / t_{a d s}=0,5, \theta=0.5$. With a stepwise change in disturbance $y_{2}^{i n}$ from 34 vol. $\%$ to 25 vol. $\%$ in the PSA unit, transient processes occur and in the 'steady state' (after about 10-15 adsorption-desorption cycles) a new optimal mode is set for a value of $y_{2}^{i n}=25$ vol.\% (Fig. 8a): $t_{a d s}^{*}=34.5 \mathrm{~s}$; $P_{a d s}^{i n *}=21 \times 10^{5} \mathrm{~Pa}, y_{1}^{\text {out }}=99.7 \mathrm{vol} \%$ at a given productivity of the unit of $Q=15 \times 10^{-3} \mathrm{~m}^{3} / \mathrm{s}$. It should be noted that a natural decrease in the proportion of $\mathrm{CO}_{2}$ in the initial gas mixture leads to an increase in product purity from 94.2 vol. $\%$ up to 96.5 vol.\% (curve 2 in Fig. 8a); however, solving the optimization problem allows to maximize this effect.

The natural stepwise increase in the proportion of $\mathrm{CO}_{2}$ in the initial gas mixture to 45 vol. $\%$ leads to a decrease in product purity to 89.5 vol.\% (curve 2 in Fig. 8b). Optimizing PSA cycles allows determining new values of process parameters for $y_{2}^{i n}=45$ vol. $\%$ (Fig. $8 \mathrm{~b}$ ): $t_{a d s}^{*}=38 \mathrm{~s}$, $P_{a d s}^{i n^{*}}=15.85 \mathrm{X} 10^{5} \mathrm{~Pa}, y_{1}^{\text {out }}=95.7 \mathrm{vol} . \%$ at a given productivity of the unit $Q=11.7 \times 10^{-3} \mathrm{~m}^{3} / \mathrm{s}$.

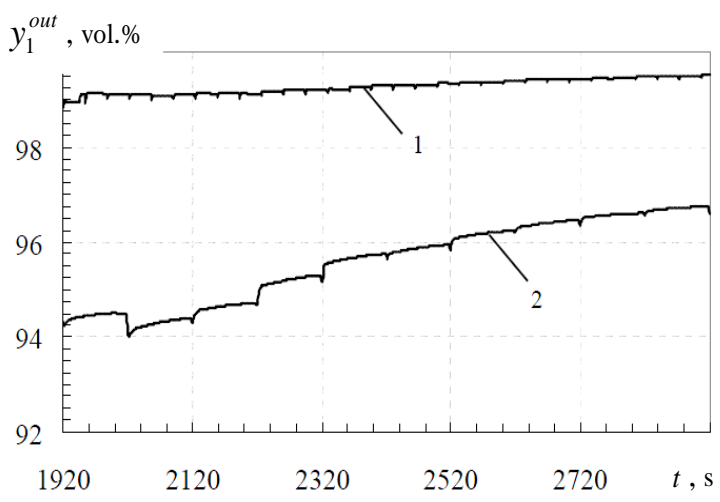

a)

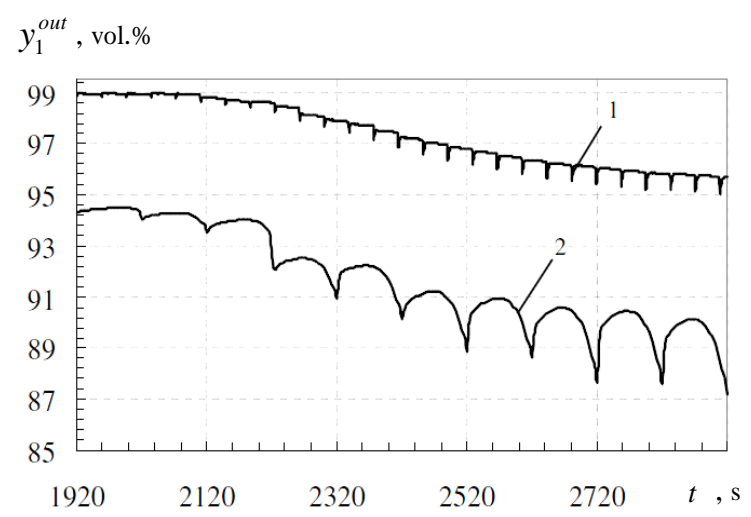

b)

Fig. 8. Transient processes in the PSA unit with a stepwise reduction to 25 vol.\% (a) and an increase to 45 vol.\% (b) in the content of $\mathrm{CO}_{2}$ in the initial mixture: 1 - when implementing the optimal mode of operation of the facility; 2- due to the self-regulation properties of the object

A discontinuous change in the temperature of the initial gas mixture from $30^{\circ} \mathrm{C}$ to $50^{\circ} \mathrm{C}$ decreases the purity of the product due to the self-regulation properties of the object to 94.13 vol.\%. Optimization of PSA unit's cycles allows the determination of new process parameter's values for $T_{g}^{i n}=50^{\circ} \mathrm{C}: \quad t_{a d s}^{*}=36 \mathrm{~s}, \quad P_{a d s}^{i n^{*}}=15.85 \times 10^{5} \mathrm{~Pa}, \quad y_{1}^{\text {out }}=98.92$ vol. $\%$ at a given productivity of the unit $Q=11.7 \times 10^{-3} \mathrm{~m}^{3} / \mathrm{s}$.

We shall now formulate the problem of optimization of the operation cycles for the PSA unit for air separation and oxygen concentration: for a given process flowsheet, a given type of adsorbent and given values of design parameters of a unit, vector $u^{*}=\left(t_{a d s}^{*}, t_{d e s}^{*}, P_{a d s}^{i n *}, P_{d e s}^{i n *}, \theta^{*}\right)$ of regime variables must be defined such that the rate of nitrogen recovery from atmospheric air $I_{1}(u)=\left(\frac{1}{t_{s t}} \int_{0}^{t_{s t}} \eta(u) d t\right)$ or productivity of the unit $I_{2}(u)=\left(\frac{1}{t_{s t}} \int_{0}^{t_{s t}} Q(u) d t\right)$ reach their maximum, i.e.

$$
I_{\lambda} \boldsymbol{l}^{*} \bar{\gamma}_{u=\left\{t_{\text {ads }}, t_{d e s}, P_{a d s}^{i n}, P_{d e s}^{i n}, \theta\right\}} I_{\lambda}(u), \lambda=1,2 .
$$

The variables are linked by equations of the mathematical model [5] and constraints are set for the concentration of the 
product oxygen, unit productivity (regarding maximal nitrogen recovery) and admissible ranges of changes of process parameters $u=\left\{t_{\text {ads }}, t_{d e s}, P_{a d s}^{i n}, P_{d e s}^{i n}, \theta\right\}$. To solve the formulated problem, the recommended above method of penalty functions (interior point) was used, as well as a method of sequential quadratic programming [10].

As the nominal mode of operation of the PSA unit in the separation of atmospheric air and the concentration of oxygen, the following values of design parameters were taken: the limiting adsorption volume of the adsorbent is $W_{0}=0.17$ $\mathrm{cm}^{3} / \mathrm{g}$, the parameter of the Dubinin thermal equation is $B=$ $6.55 \times 10^{-6} 1 / \mathrm{K}^{2}$, the height of the bulk layer of the adsorbent is $H_{L}=0.3 \mathrm{~m}$, the diameter of the adsorber is $D_{A}=H / 6 \mathrm{~m}$, the diameter of the adsorbent granules is $d_{g}=10^{-3} \mathrm{~m}$, the volume of the receiver is $V_{R}=0.2405 \times 10^{-3} \mathrm{~m}^{3}$. The assumed process parameters were composition of atmospheric air in the feed of the PSA unit for oxygen concentration - $y_{1}^{i n}=20.8$ vol. $\%$, nitrogen concentration - $y_{2}^{i n}=78.2 \mathrm{vol} . \%$, argon concentration - $y_{3}^{\text {in }}=1$ vol. $\%$; volume flow $G^{\text {in }}=17 \times 10^{-5} \mathrm{~m}^{3} / \mathrm{s}$ and ambient air temperature of $20^{\circ} \mathrm{C}$, target values of product oxygen concentration $y_{1}^{\text {out }} \geq 90$ vol. $\%$ and capacity of the unit $Q \geq 0,85 \cdot 10^{-5} \mathrm{~m}^{3} / \mathrm{s}$. were:

The permissible ranges of variation in process variables

1) for the pressure circuit: $1 \leq t_{\text {ads }} \leq 15,1 \leq t_{\text {des }} \leq 15$, $2 \times 10^{5} \leq P_{a d s}^{i n} \leq 6 \times 10^{5}, P_{d e s}^{i n}=1 \times 10^{5}, 0 \leq \theta \leq 1 ;$

2) for the vacuum-pressure circuit: $1 \leq t_{a d s} \leq 15$, $1 \leq t_{d e s} \leq 15,2 \times 10^{5} \leq P_{a d s}^{i n} \leq 6 \times 10^{5}$, $0,5 \times 10^{5} \leq P_{d e s}^{i n} \leq 1 \times 10^{5}, 0 \leq \theta \leq 1$.

The maximum value of the average degree of nitrogen recovery $\eta^{*}=99,93 \%$ is achieved with the following values of the regime variables:

1) for the pressure circuit: $t_{a d s}^{*}=3.1 \mathrm{~s}, \quad t_{d e s}^{*}=4 \mathrm{~s}$, $P_{a d s}^{i n *}=4.2 \times 10^{5} \quad \mathrm{~Pa}, \quad \theta^{*}=0.82$; the 'steady-state' mode of operation is achieved after $n_{s t}^{*}=17$ adsorption-desorption cycles;

2) for the vacuum-pressure circuit: $t_{a d s}^{*}=3.1 \mathrm{~s}, t_{d e s}^{*}=3.5 \mathrm{~s}$, $P_{a d s}^{i n *}=6 \times 10^{5} \mathrm{~Pa}, P_{d e s}^{i n *}=0.99 \times 10^{5} \mathrm{~Pa}, \theta^{*}=0.7, n_{s t}^{*}=35$.

The PSA unit achieves its maximum productivity level when the regime variables are as following:

1) for the pressure circuit: $Q^{*}=1.6 \times 10^{-5} \mathrm{~m}^{3} / \mathrm{s}, t_{a d s}^{*}=4.3 \mathrm{~s}$, $t_{d e s}^{*}=3.8 \mathrm{~s} P_{a d s}^{i n *}=6 \times 10^{5} \mathrm{~Pa}, \theta^{*}=0.61, n_{s t}^{*}=22$;
2) for the vacuum-pressure circuit: $Q^{*}=1.8 \times 10^{-5} \mathrm{~m}^{3} / \mathrm{s}$, $t_{a d s}^{*}=4.16 \mathrm{~s}, \quad t_{d e s}^{*}=4.16 \mathrm{~s}, \quad P_{a d s}^{i n *}=5.93 \times 10^{5} \quad \mathrm{~Pa}$, $P_{d e s}^{i n *}=0.99 \mathrm{X} 10^{5} \mathrm{~Pa}, \theta^{*}=0.48, n_{s t}^{*}=29$.

\section{CONCLUSIONS}

Modern methods of system analysis and mathematical modeling have allowed to obtain new scientific results which can be efficiently implemented: 1) for formulating and solving problems of optimization of the cycles of adsorption separation of synthesis gas and atmospheric air in order to concentrate hydrogen and oxygen with purity of $99.9 \%$ and $90 . .95$ vol.\%, respectively; 2) for the optimal design of new automated processes and PSA installations with cyclically variable pressure for separation and purification of multicomponent gas mixtures; 3 ) for the optimal design of smallscale medical oxygen concentrators and novel on-board oxygen generating units.

\section{Acknowledgment}

The authors are grateful to A. Ishin, Ph.D. for providing experimental data to verify the adequacy of the mathematical model and assisting in carrying out computational experiments, as well as the Ministry of Education and Science of Russia for funding the research under Grant No. 10.3533.2017.

\section{References}

[1] Y.I. Sumyatsky, "Industrial adsorption processes", Moscow, 2009.

[2] D.M. Ruthven, S. Farooq and K. S. Knaebel, "Pressure swing adsorption", New York, 1994.

[3] N.V. Keltsev, "Basics of adsorption technology", Moscow, 1984.

[4] E.I. Akulinin, A.A. Ishin, S.A. Skvortsov, D.S. Dvoretskiy, and S.I. Dvoretsky, "Mathematical modeling of hydrogen production process by pressure swing adsorption method", Advanced Materials and Technologies, N. 2. pp. 38-49, 2017.

[5] E.I. Akulinin, D.S. Dvoretsky, S.I. Dvoretsky and E.N. Tugolukov, "Modeling of the process of air enrichment with oxygen in a pressure swing adsorption installation", Chemical Technology, N.4, pp. $247-$ 256, 2012.

[6] D. Ko, R. Siriwardane and L. Biegler, "Optimization of pressure swing adsorption and fractionated vacuum pressure swing adsorption processes for $\mathrm{CO}_{2}$ capture", Industrial \& Engineering Chemistry Research, vol. 44 (21), pp. 8084-8094, 2005.

[7] M. Baksh and M. Ackley, "Pressure swing adsorption process for the production of hydrogen", Patent US 6340382, 2002.

[8] S. Gittleman, W. Appel, D. Winter, and B. Sward, "Hydrogen purification process using pressureswing adsorption for fuel cell applications", Patent US 0098034, 2005.

[9] Y. Park, S. Lee, J. Moon, D. Choi and C. Lee, "Adsorption equilibria of O-2, N-2, and Ar on carbon molecular sieve and zeolites 10X, 13X, and LiX”, Journal of Chemical and Engineering Data, vol. 51 (3), pp. 10011008, 2006.

[10] V.A. Kirillin, V.V. Sychev and A.E. Sheindlin, "Technical thermodynamics", Moscow, 2008.

[11] E. Shokroo, D. Farsani, H. Meymandi and N. Yadoliahi, "Comparative study of zeolite 5A and zeolite $13 \mathrm{X}$ in air separation by pressure swing adsorption”, Korean Journal of Chemical Engineering, vol. 33 (4), pp. 1391-1401, 2016.

[12] G. Recleitis, A. Reivindrane and C. Regsdaile, "Optimization in engineering", Moscow, 1986. 